\title{
A new generation of smart amine donors for transaminase- mediated biotransformations
}

Andrew Gomm ${ }^{[\mathrm{a}]}$, William Lewis ${ }^{[\mathrm{a}]}$, Anthony P. Green ${ }^{[\mathrm{b}]}$, and Elaine O’Reilly ${ }^{[\mathrm{a}] *}$

\begin{abstract}
The application of $\omega$-transaminase biocatalysts for the synthesis of optically pure chiral amines presents a number of challenges, including difficulties associated with displacing the challenging reaction equilibria. Herein, we report a highly effective approach using low equivalents of the novel diamine donor, cadaverine, which enables high conversions of challenging substrates to the corresponding chiral amines in excellent ee. This approach paves the way for the design of self-sufficient fermentation processes combining transaminase biotransformations with existing strategies for cadaverine production via decarboxylation of endogenous lysine.
\end{abstract}

Chiral amines are prevalent in active pharmaceutical ingredients (APIs) and frequently feature as functional handles in widely used chemical building blocks. ${ }^{1}$ However, cost effective and sustainable access to optically pure derivatives continues to present a significant challenge for the pharmaceutical and chemical industries. In recent years, biocatalysis has emerged as a competitive and sustainable technology for the production of high-value chemicals. ${ }^{2}$ There has been a notable surge in the discovery and development of novel biocatalysts and biocatalytic processes for the preparation of optically pure amines, including those involving amine oxidases, ${ }^{3}$ ammonia lyases, ${ }^{4}$ imine reductases, ${ }^{5}$ amine dehydrogenase ${ }^{6}$ and $\omega$-transaminases $\left(\omega\right.$-TAs). ${ }^{3 \mathrm{~d}, 7}$

$\omega$-TAs in particular are emerging as extremely promising catalysts for chiral amine synthesis, starting from readily available prochiral ketones. These pyridoxal-5'-phosphate (PLP)dependent proteins are part of the aminotransferase class of enzyme (EC 2.6.1.18) and rely on a sacrificial amine donor to mediate the reversible conversion of structurally diverse ketones to the corresponding chiral primary amines. ${ }^{8}$ The development of a transaminase-catalyzed manufacturing route to the blockbuster antidiabetic drug sitagliptin, using a heavily engineered $(R)$-selective $\omega$-TA, highlights the high level of interest in this enzyme family. ${ }^{7 \mathrm{a}}$ However, despite the enormous synthetic potential of these biocatalysts, there remain limited examples of their application in industry. Challenges associated with overcoming unfavourable reaction equilibria as well as a restricted substrate scope has contributed to the relatively slow uptake of these biocatalysts in both academia and industry.

Biotransformations employing $\omega$-TAs

[a] A. Gomm, Dr. W. Lewis, Dr. E. O'Reilly

School of Chemistry, University of Nottingham

University Park, NG7 2RD, UK

E-mail: elaine.oreilly@nottingham.ac.uk

[b] Dr. A. P. Green

Manchester Institute of Biotechnology, University of Manchester 131 Princess Street, Manchester, M1 7DN typically involve the use of a large excess of isopropylamine (IPA) as a low-cost donor combined with in-situ evaporation of the acetone by-product to displace reaction equilibria towards product formation. ${ }^{7 \mathrm{a}}$ However, to obtain the low concentrations of acetone 
required to achieve high conversions presents a significant technical challenge. In addition, this methodology cannot be successfully applied for the conversion of ketones with particularly challenging positions of equilibria. ${ }^{9}$ Alternative methods employed to displace reaction equilibria involve combinations of expensive enzymes, which function to remove the by-product and recycle costly co-factor. ${ }^{3 \mathrm{~d}, 7 \mathrm{~b}-\mathrm{c}, 10}$ We have recently reported an extremely efficient strategy, which allows high conversions to be obtained using only 1.0 equivalent of the 'smart' diamine donor, $o$-xylylenediamine. ${ }^{11}$ The success of this approach can be attributed to spontaneous cyclization, tautomerization and irreversible polymerization of the by-product, which prevents the reverse reaction from compromising conversion. However, in addition to the relatively high cost of $o$-xylylenediamine (compared to IPA), the formation of coloured polymeric by-products has the potential to complicate downstream processing and product purification and therefore there remains considerable demand for the discovery of alternative 'smart' amine donors. In conjunction with effectively displacing challenging reaction equilibria, these new smart donors should be derived from bulk chemicals in order to be suitable for industrial scale chiral amine production.

Diamines 1-6 (Scheme 1 (a)) were selected for initial evaluation, as the aminoaldehyde byproducts of these donors have the potential to dimerize or cyclise in a similar manner to $o$ xylylenediamine, but are not expected to lead to the formation of insoluble polymers (Scheme 1 (b)). A key challenge was to identify an $\omega$-TA biocatalyst capable of accepting these diamines to enable their suitability as amine donors to be evaluated. Importantly, this $\omega$-TA must also have broad substrate scope towards structurally diverse ketones.

a)
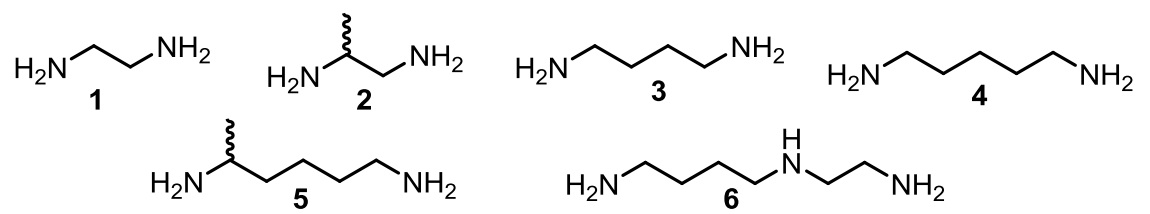

b) i)

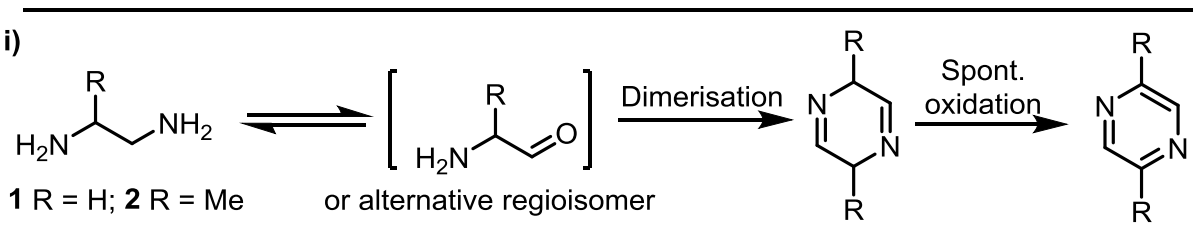

ii)

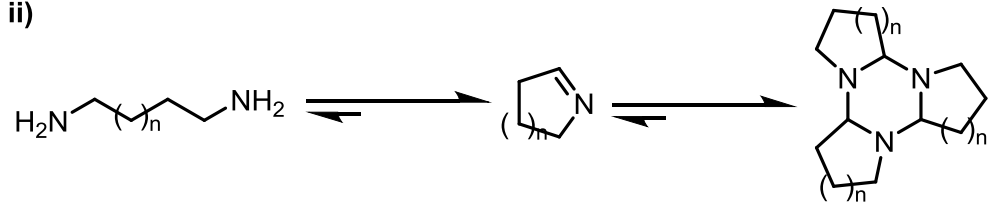

Scheme 1. (a) Amine donors 1-6 screened with commercial enzymes and (b) predicted dimerization or cyclization of the by-products. (i) The aminoaldehyde by-products of $\mathbf{1}$ and $\mathbf{2}$ have the potential to undergo dimerization followed by spontaneous and irreversible oxidation to the pyrazine. (ii) The by-products of diamines 3-5 are expected to cyclize to the corresponding pyrroline or tetrahydropyridine and undergo further trimerization.

While there are examples of diamino- and poly aminotransferases that accept similar amine donors, ${ }^{12}$ these enzymes suffer from an extremely narrow ketone substrate scope, which is thus far limited to alpha-keto acids. In contrast, commercially available $\omega$-TAs from Codexis offer an extremely broad substrate scope and have been engineered for increased stability, 
making them the biocatalysts of choice in both academic and industrial laboratories. Therefore, our initial screen focused on evaluating twelve optimized Codexis biocatalysts ${ }^{13}$ for their ability to utilize diamines 1-6. This preliminary screen, with 1.0 equivalent of donors 1-6 and acetophenone as the acceptor, revealed donors $\mathbf{4}$ and $\mathbf{5}$ allowed significant conversion of the ketone to the corresponding chiral amine using $(S)$-selective ATA256 at $\mathrm{pH} 8.5$ (preliminary data not shown). Having identified ATA256 as a suitable biocatalyst, the conversion of acetophenone to MBA was monitored at a range of $\mathrm{pH}$ values using both diamine 4 and IPA as the amine donor (Figure 1). Despite this commercial enzyme being specifically engineered to accept high concentrations of IPA, cadaverine (also referred to as 1,5-DAP) outperformed this donor across all three $\mathrm{pH}$ ranges tested. With both donors, increasing the reaction $\mathrm{pH}$ resulted in higher conversions. Significantly, only modest enhancements in conversions with increasing $\mathrm{pH}$ were obtained using the standard IPA donor. In contrast, conversions with cadaverine increased dramatically upon variation of $\mathrm{pH}$ from 9 to 10.9 (a more detailed discussion of the effect of $\mathrm{pH}$ is given below).

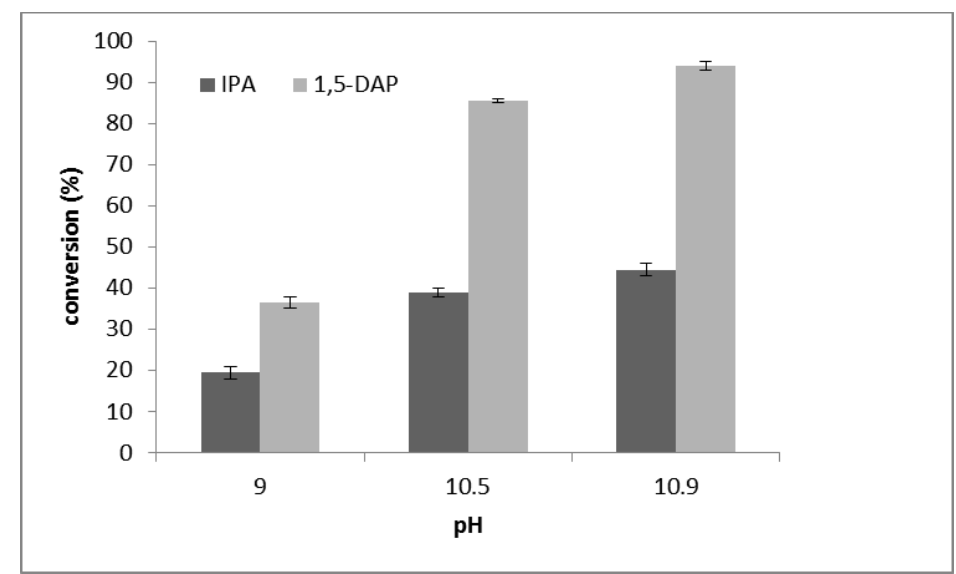

Figure 1. $\mathrm{pH}$-profile for the conversion of acetophenone to (S)-MBA using 3 equivalents of IPA and 1,5-DAP as the amine donors. Conversions are reported after 48 hours. The values given are the mean of 2-3 repeats and the error bars represent the upper and lower limits of conversions obtained for individual reactions.

Having established the optimum $\mathrm{pH}$ for performing these reactions, ATA256 was screened with ketones 7-9 and amine donors 4 and 5 (Table 1). In each case, the conversions were compared to those achieved using IPA as the amine donor. The ketone substrates (7-9) were rationally selected to allow the efficiency of these diamine donors to be evaluated in combination with progressively challenging substrates. Biocatalytic amination of 7-9 becomes successively more challenging due to increasingly unfavourable positions of thermodynamic equilibria, as determined previously with alternative amine donors. ${ }^{11}$

Using only 1.5 equivalents of diamine 4, essentially complete conversion (96\%) of 4fluorophenylacetone 7 to $(S)$-4-fluoroamphetamine was achieved. Under the same conditions, a modest conversion of $69 \%$ was observed using IPA.

Acetophenone is routinely used as a benchmark substrate in $\omega$-TA biotransformations. An impressive conversion of $94 \%$ was achieved for this aromatic ketone with only 3.0 equivalents of diamine 4 , while under the same conditions, IPA enabled only a modest conversion of $44 \%$. 
Table 1. Conversion of 7-9 to the corresponding amines using ATA256 and diamines 4, 5 and IPA.

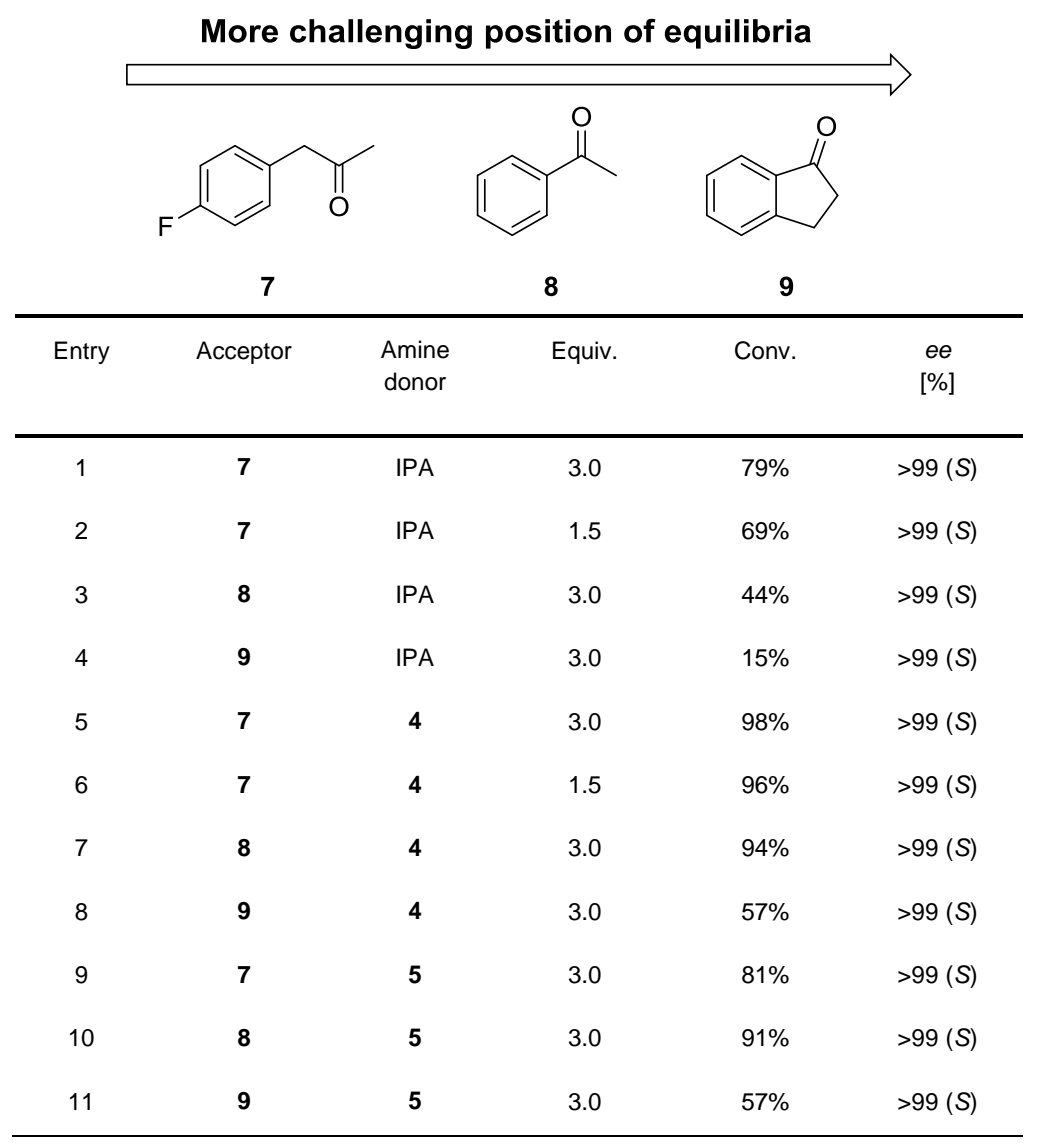

The ketone concentration was 20mM. Conversions are calculated from the mean of 3-5 replicates. ee values were measured by GC-FID using a chiral column (see supporting information).

The conversion of 1 -indanone 9 to aminoindane is known to be particularly challenging due to the extremely unfavourable position of equilibria associated with this transformation. We recently reported that $1.5 \mathrm{eq}$ of $o$-xylylenedimaine was sufficient to achieve a $73 \%$ conversion to the corresponding chiral amine. ${ }^{11}$ In the same study we reported that a modest conversion (21\%) was achieved using 10 eq of alanine and the widely used lactate dehydrogenase/glucose dehydrogenase pyruvate removal system. Using only 3.0 eq of 1,5DAP, a 54\% conversion of 9 to $(S)-(+)-1$-aminoindane is achieved demonstrating the ability of this diamine donor to displace the equilibria of extremely challenging substrates. Under the same conditions, IPA performed poorly as expected, reaching only $15 \%$ conversion after 48 hours. The conversions with substrates 7-9 obtained with the related diamine 5 were broadly comparable to those achieved with 1,5-DAP (Entries 9-11).

The conversion of acetophenone $\mathbf{8}$ to MBA was subsequently carried out on a preparative scale (Scheme 2 (b)) to demonstrate the suitability of this system for performing preparative scale transformations and to allow by-product characterization. We anticipated that the fate of the initially formed cyclic imine by-product may provide a rationale for the dramatic increase in conversions with increasing $\mathrm{pH}$. To aid by-product characterization, imine $\mathbf{1 2}$ was prepared synthetically following a literature procedure ${ }^{14}$ (Scheme 2 (a)). The symmetrical product 13 
was initially isolated exclusively and subsequently converted to isotripiperidine $14 .{ }^{14}$ The unsymmetrical trimer was characterised by mass spectrometry and $\mathrm{NMR}^{14,15}$ and the $\mathrm{x}$-ray crystal structure of the molecule was solved (Scheme 2 (c)). Only trimer 14 was observed in the preparative scale biotransformation (Scheme 2 (b)) by both GC and NMR (see supporting information Figure S1 for NMR overlay) and could be seperated from the chiral amine product by filtering through silica. This result is in line with literature reports that this trimer is stable at $\mathrm{pH} 10^{16}$ and may rationalise why a higher reaction $\mathrm{pH}$ leads to increased conversions.

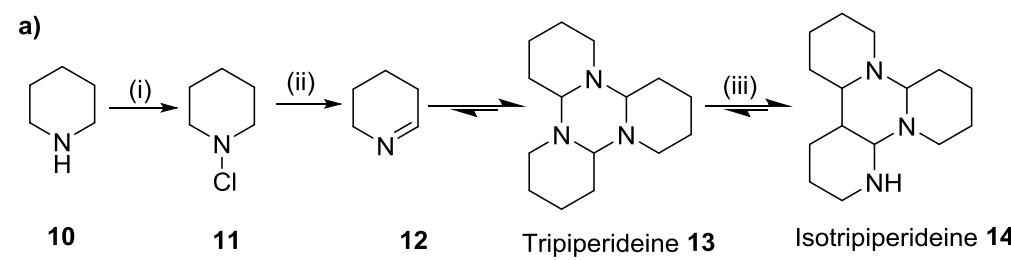

b)

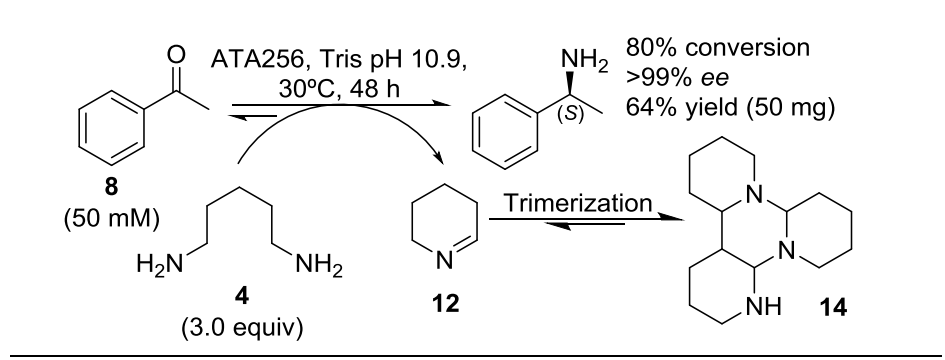

c)

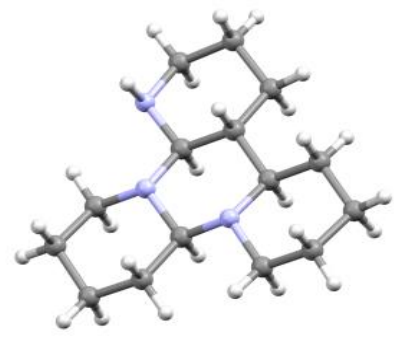

Scheme 2. a) Synthesis of tripiperidine 13 and unsymmetrical isotripiperidine $14 .{ }^{14}$ (i) $\mathrm{N}$-Chlorosuccinimide, $\mathrm{Et}_{2} \mathrm{O}, 0^{\circ} \mathrm{C}, 2 \mathrm{~h}$; (ii) $\mathrm{EtOH}, \mathrm{KOH}$, reflux, 2 h, $68 \%$ over two steps; (iii) recrystallized in acetone, $-20{ }^{\circ} \mathrm{C}, 5$ days. b) Preparative-scale biotransformation of acetophenone 8 to $(S)$-MBA using ATA256 and 1,5-DAP 4. c) Crystal structure of isotripiperidine 14.

To determine whether the formation of trimer $\mathbf{1 4}$ is reversible under biotransformation conditions and to further investigate the influence of $\mathrm{pH}$ on reaction equilibria, purified trimer 14 was evaluated as an amine acceptor in combination with $(S)$-aminoindane 15 (i.e. the reverse process of entry 8 , Table 1), at a range of $\mathrm{pH}$ values ( $\mathrm{pH} 8$-10.9) (Table 2). Table 2 shows that at $\mathrm{pH} 8,(S)$-aminoindane 15 is readily converted to indanone $9(68 \%)$ while at higher $\mathrm{pH}$ values, this conversion is much less efficient. At $\mathrm{pH} 10.9$ (the optimal reaction conditions employed in this study) a modest conversion of $14 \%$ was achieved. These results suggest that formation of unsymmetrical trimer $\mathbf{1 4}$ is favoured at higher $\mathrm{pH}$ and that trimer 
formation contributes to the displacement of the thermodynamic equilibrium towards the desired amine products.

Table 2. Conversion of amine acceptor 14 to cadaverine 4 using ATA256 and $(S)$-aminoindane over pH range 8-10.9.

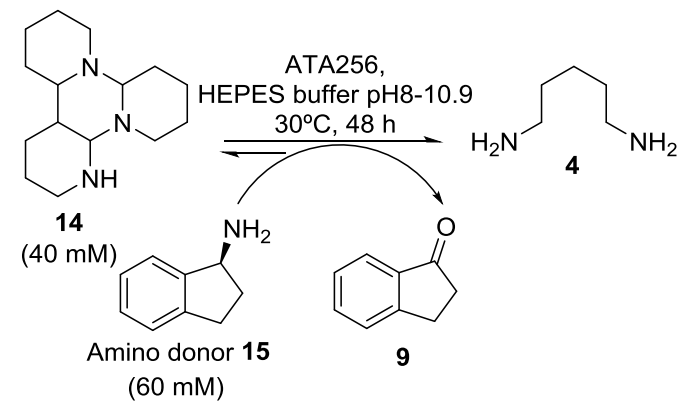

\begin{tabular}{cccccc}
\hline Entry & ATA & Amine donor & Acceptor & pH & Conv. \\
\hline 1 & 256 & $\mathbf{1 5}$ & $\mathbf{1 4}$ & 8.0 & $68 \%$ \\
2 & 256 & $\mathbf{1 5}$ & $\mathbf{1 4}$ & 9.0 & $57 \%$ \\
3 & 256 & $\mathbf{1 5}$ & $\mathbf{1 4}$ & 10 & $28 \%$ \\
4 & 256 & $\mathbf{1 5}$ & $\mathbf{1 4}$ & 10.9 & $14 \%$
\end{tabular}

Conversions are based on the formation of ketone 9 from $(S)$-aminoindane 15, monitored by GC-FID.

In summary, we have identified an $\omega$-TA that has broad acceptor substrate scope and is capable of using the bulk diamine cadaverine as an amine donor. This new generation 'smart' diamine is highly effective at displacing challenging reaction equilibria, enabling high conversions to the desired optically pure chiral amine products in the absence of by-product removal systems. The success of this donor can be attributed to a spontaneous dehydrative cyclization/trimerization of the reaction byproduct following transamination. In all cases, cadaverine significantly outperforms the industry standard amine donor, isopropylamine, and therefore this work represents an important proof-of-concept study. Future efforts will focus on the identification of $\omega$-TAs that accept alternative bulk diamines (including 1,4-diaminobutane or putrescine), performing reactions at significantly higher substrate concerntrations and exploring the potential of self-sufficient fermentation processes whereby the cadaverine donor is produced biosynthetically via lysine decarboxylation.

\section{Acknowledgements}

Research leading to these results has received funding from the BBSRC (BB/M021947/1), EPSRC (EP/K038869/1) and RSC Research Fund. We also gratefully acknowledge a Royal Society Research Grant (RG150134) and Codexis for supplying enzymes used in this study.

Keywords: asymmetric catalysis $\bullet$ biocatalysis $\bullet$ chiral amine $\bullet$ diamine $\bullet$ transaminase 


\section{References}

[1] a) N. M. Cassiano in Alkaloids: Properties, Applications and Pharmacological Effect, Nova Science Pub. Inc.; New York, 2010; b) M. E. Welsch, S. A. Snyder, B. R. Stockwell, Curr. Opin. Chem. Biol. 2010, 14, 347; c) D. J. Newman, G. M. J. Cragg, Nat. Prod. 2012, 75, 311.

[2] a) N. J. Turner, M. D. Truppo in Biocatalytic routes to nonracemic chiral amines, Wiley_VCH Verlag GmbH, 2010, pp 431-459; b) M. Höhne, U. T. Bornscheuer, ChemCatChem 2009, 1, 42; c) C. M Clouthier, J. N. Pelletier, Chem. Soc. Rev., 2012, 41, 1585-1605.

[3] a) C. J. Dunsmore, R. Carr, T. Fleming, N. J. Turner, J. Am. Chem. Soc. 2006, 128, 2224; b) D. Ghislieri, A. P. Green, M. Pontini, S. C. Willies, I. Rowles, A. Frank, G. Grogan, N. J. Turner, J. Am. Chem. Soc. 2013, 135, 10863; c) D. Ghislieri, D. Houghton, A. P. Green, S. C. Willies, N. J. Turner, ACS Catal. 2013, 3, 2869; d) E. O’Reilly, C. Iglesias, N. J. Turner, ChemCatChem 2014, 6, 992.

[4] a) M. M. Heberling, B. Wu, S. Bartsch, D. B. Janssen, Curr. Opin.Chem. Biol. 2013, 17, 250; b) S. L. Lovelock, R. C. Lloyd, N. J. Turner, Angew. Chem. Int. Ed. 2014, 53, 4652; Angew. Chem. 2014, 126, 4740; c) F. Parmeggiani, S. L. Lovelock, N. J. Weise, S. T. Ahmed, N. J. Turner, Angew. Chem. Int. Ed., 2015, 54, 4608-4611; Angew. Chem., 2015, 127, 4691-4694.

[5] a) F. Leipold, S. Hussain, D. Ghislieri, N. J. Turner, ChemCatChem 2013, 5, 3505; b)

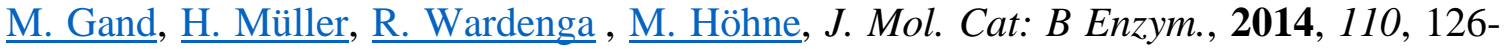
132; c) P. N. Scheller, S. Fademrecht, S. Hofelzer, J. Pleiss, F. Leipold, N. J. Turner, B. N. Nestl, B. Hauer, Chembiochem. 2014,15, 2201-4; d) S. Hussain, F. Leipold, H. Man, E. Wells, S.P. France, K. R. Mulholland, G. Grogan, N. J. Turner, ChemCatChem, 2015, 7, 579-583.

[6] M. J. Abrahamson, E. Vazquez-Figueroa, N. B. Woodall, A. S. Bommarius, Angew. Chem. Int. Ed. 2012, 51, 3969; Angew. Chem. 2012, 124, 4036; b) M. J. Abrahamson, J. W. Wong, A. S. Bommarius, 2013, Adv. Synth. Catal., 355, 1780-1786; c) L. J. Ye, H. H. Toh, Y. Yang, J. P. Adams, R. Snajdrova, Z. Li, ACS Catalysis, 2015, 5, 1119-1122.

[7] a) C. K. Savile et al., Science 2010, 329, 305; b) E. O’Reilly, C. Iglesias, D. Ghislieri, J. Hopwood, J. L. Galman, R. C. Lloyd, N. J. Turner, Angew. Chem. Int. Ed. 2014, 53, 2447; Angew, Chem. 2014, 126, 2479; c) E. O'Reilly, N. J. Turner, Perspectives in Science 2015, 4, 55- 61; d) T. Sehl, H. C. Hailes, J. M. Ward, R. Wardenga, E. von Lieres, H. Offermann, R. Westphal, M. Pohl, D. Rother, Angew. Chem. Int. Ed., 2013, 52, 6772-6775; Angew. Chem., 2013, 125, 6904-6908; e) A. Cuetos, M. García-Ramos, E.-M. Fischereder, A. Díaz-Rodríguez, G. Grogan, V. Gotor, W. Kroutil, I. Lavandera, Angew. Chem. Int. Ed. 2016, 55, 3144; Angew. Chem. 2016, 128, 3196.

[8] a) S. Mathew, H. Yun, ACS Catal. 2012, 2, 993; b) D. Koszelewski, K. Tauber, K. Faber, W. Kroutil, Trends Biotechnol. 2010, 28, 324.

[9] a) P. Tufvesson, C. Bach, J. M. Woodley, Biotechnol. Bioeng. 2014, 111, 309-319.

[10] a) B. Wang, H. Lan, P. Berglund, Chem. Commun., 2013, 49, 161-163; b) L. MartínezMontero, V. Gotor, V. Gotor-Fernández, I. Lavandera, Adv. Synth. Catal., 2016, 358, 1618-1624; c) D. Koszelewski, I. Lavandera, D. Clay, G. M. Guebitz, D. Rozzell, W. 
Kroutil, Angew. Chem., Int. Ed. 2008, 47, 9337; Angew. Chem. 2008, 120, 9477; d) R. Abu, J. M. Woodley, ChemCatChem, 2015, 7, 3094.

[11] A. P. Green, N. J. Turner, E. O'Reilly, Angew. Chem. Int. Ed. 2014, 53, 10714; Angew. Chem. 2014, 126, 10890.

[12] I. Slabu, J. L. Galman, N. J. Weise, R. C. Lloyd, N. J. Turner, ChemCatChem, 2016, 8, 1038-1042.

[13] The following TA biocatalysts were screened: ATA254, ATAG05, ATA260, ATA256, ATA234, ATA113; (R)-selective ATA025, ATA303, ATA013, ATA301, ATA415, ATA117.

[14] E. Gravel, E. Poupon, R. Hocquemiller, Tetrahedron 2006, 62, 5248-5253. It is worth noting that our ${ }^{1} \mathrm{H}$ MNR data for compound $\mathbf{1 4}$ is not fully consistent with the data reported in this manuscript.

[15] H. Keske, H. Möhrle, G. Zimmermann, J. Org. Chem. 1977, 42, 66-72.

[16] A. Rouchaud, A., J. -C. Braekman, Eur. J. Org. Chem., 2009, 2666-2674. 